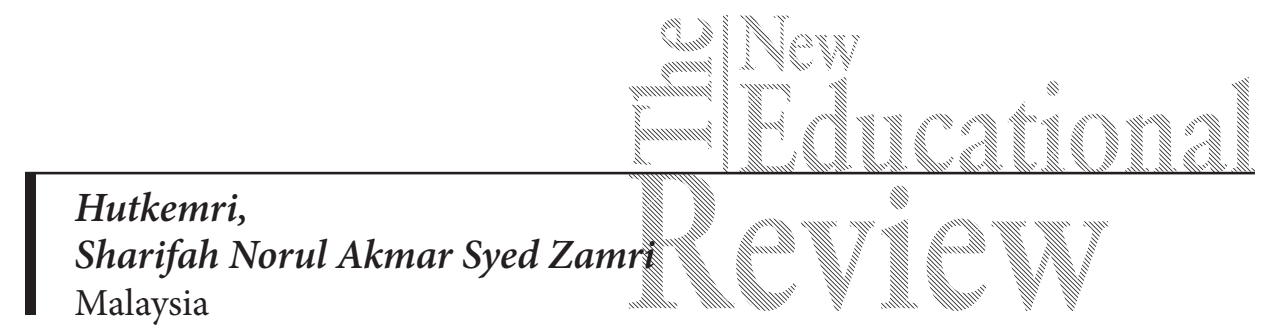

\title{
Effectiveness of Geogebra on Academic and Conceptual Knowledge: Role of Students' Procedural Knowledge as a Mediator
}

DOI: 10.15804/tner.2016.44.2.12

\begin{abstract}
Quasi-experimental research was conducted to identify the effectiveness of GeoGebra in achieving students' conceptual and procedural knowledge. The research was performed to identify the effects of a mediator in students' conceptual knowledge in relation to procedural knowledge with student achievement. A total of 284 students were involved in this study. The students in the experimental group learned using GeoGebra, whereas the students in the control group used the conventional method. The collected data were analyzed using SPSS 22.0, AMOS 18, and Anates V4. Findings of the study demonstrate that GeoGebra is used as a mediator of students' procedural knowledge in relation to conceptual knowledge for academic achievement. This study also shows that conceptual knowledge affected the students' mathematics procedures. The result of the study supports the related theory of the role and contribution of conceptual and procedural knowledge to student achievement. This study provides suggestions as intervention to increase students' conceptual and procedural knowledge.
\end{abstract}

Keywords: achievement, conceptual and procedural knowledge, GeoGebra, limit function, mediator, quasi-experimental

\section{Introduction}

Select computer software can be used to help students become more responsible for their own learning through creative and interesting exploration in calculus (Ahmad Fauzi et al., 2009). Previous studies proved that using technology in 
education increases motivation and the confidence level, improves problem-solving skills, and produces an excellent future generation (Sivin-Kachala and Bialo, 2000; Oldknow and Taylor, 2000). The introduction of technology in industry also provides an opportunity for educators to embed such technology in their teaching and learning. Teachers are no longer playing the traditional role of educators; instead, they become facilitators with the use of computers. Rohani et al. (2009) stated that technology in teaching and learning of mathematics helps in the basic understanding of this subject and developing intuition in solving mathematical problems. Teachers must be prepared and willing to accept the current change and use the latest technology in the classroom.

GeoGebra helps teachers in the teaching and learning process of the mathematics subject. GeoGebra is dynamic mathematical software for geometry, algebra, and calculus (Rincon, 2009). GeoGebra is alternative software for teachers in integrating technology in the teaching and learning process of mathematics (Aizikovitsh and Radakovic, 2011). Furthermore, many people suggested GeoGebra in activities that involve mathematical concepts. In addition to being a tool to understand a concept, GeoGebra is also used to explain a procedure. The most interesting part of GeoGebra is the online community comprising regular users, who contribute and share their own teaching materials free of charge. The use of GeoGebra in the teaching and learning of mathematics is a method of effective learning, and it is particularly useful in the topics of geometry, algebra, and calculus (Rincon, 2009).

Williams (1991) stated that students' difficulty in conceptual calculus ranges from the basic concept of all standard modern analyses to the traditional pedagogy of introduction to calculus. This difficulty is a problem for teachers who are trying to teach this concept. The mathematical approach to limit and its cognitive approach differ slightly. One of the causes of this problem is that the teaching process is more focused on the syllabus content. A few studies found that conceptual and procedural knowledge on limit function among students is low (Setu, 2012). This situation may be caused by the functional concept that combines different modern mathematical topics, and the limit functional concept has a focused role (Selden and Selden, 1992). Research must be conducted to obtain clear information on the conceptual and procedural knowledge of students. Carpenter (1986) stated that the relationship between conceptual and procedural knowledge is not easy because of the continuous problems in conceptual knowledge. This knowledge is difficult to measure directly and is usually observed in certain procedures.

Previous studies of GeoGebra in mathematics did not focus on students' conceptual and procedural knowledge. Experimental studies were performed to 
determine the effectiveness of GeoGebra in teaching (Aizikovitsh and Radakovic, 2011). The studies focused more on proving that GeoGebra could be used to teach mathematics. Thus, GeoGebra should be shown as a means to solve students' problem in limited function topic. In this case, teachers must select the most appropriate teaching strategies that can support their teaching process. The most suitable teaching strategies are required to guarantee the best achievement in any possible way (Slameto, 2003). Previous studies proved that students had difficulty understanding the concept of limit (Juter 2006; Pettersson and Scheja, 2008). This is viewed as a process on the function (Williams, 1991). Tall and Vinner (1981) suggested that if students' conceptual image is influenced by a dynamic process, they will have the wrong impression of not achieving the limit. Students focus on the limit especially regarding the procedures that should be followed and explain concepts based on their understanding (Pettersson and Scheja, 2008).

\section{Conceptual Knowledge}

The basic difference between conceptual and procedural knowledge was suggested by Hiebert (1986). According to Hiebert and Lefevre (1986), conceptual knowledge is knowledge that is rich with relations. Star (2005) stated that conceptual knowledge is understood as knowledge about concepts or principles and procedural knowledge as knowledge about procedures.

\section{Procedural Knowledge}

Procedural understanding refers to a level of understanding that involves numerous facts and algorithms, and it does not require idea-based knowledge (Hope, 2006). Procedural knowledge is considered a basic skill that must be learned by students.

\section{Academic Achievement}

Academic achievement means students' ability and skill to learn subjects at school (Robiah, 1994). In other words, achievement in this study means the success of students in examinations at school. The achievement data are collected from mathematics teachers at school. Kiuru et al. (2014) stated that student 
achievement could be improved if teachers could support students by preparing suitable teaching methods that interested them.

The present study was conducted to identify the effectiveness of GeoGebra in conceptual and procedural knowledge, including student achievement. The study also aims to highlight the effect of students' conceptual knowledge in the relation between procedural knowledge and student achievement.

The hypothesized path model is shown in Figure 1. The following specific research questions are addressed by fitting the hypothesized structural models to the data and estimating their parameters:

(i) Does conceptual knowledge contribute to mathematical procedures between students who used GeoGebra and those who used the conventional method?

(ii) Does conceptual knowledge have any direct contribution to the achievement of students who used GeoGebra and those who used the conventional method?

(iii) Does conceptual knowledge have any contribution to the achievement through the mediator of procedural knowledge between the students who used GeoGebra and those who used the conventional method?

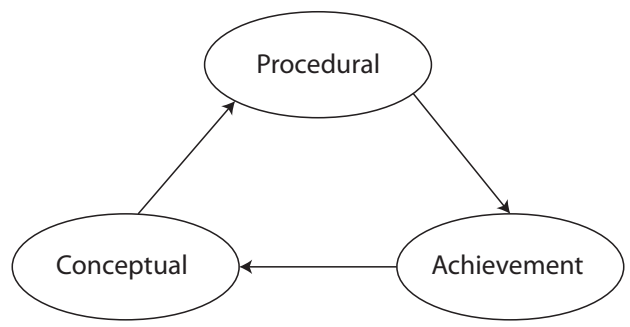

Figure 1. Hypothesized contribution model with conceptual and procedural knowledge and achievement.

\section{Method}

\section{Participants and procedure}

A total of 284 form-2 students from secondary school were involved as participants in this study. A total of 136 students used GeoGebra in their learning, and 148 used the conventional method. The students were randomly selected. Quasi-experimental research and non-equivalent pretest and post-test control group design were conducted. Data were collected using test questions on mathematical conceptual 
and procedural knowledge of the limited function topic with five questions. The test on mathematical conceptual and procedural knowledge on similar topic is based on the study conducted by Best and Kahn (2003). The instrument of this test was verified by the teaching experts in calculus. The pilot study was conducted with 60 secondary school students to determine the validity of discrimination and difficulty index of each question. The data from the pilot study were analyzed using the ANATES V4 software, and the result demonstrates that each item in the questions has the discrimination and difficulty index between $48.44 \%$ and $69.53 \%$ on average (Karno, 1996) and a high validity level between 0.82 and 0.83 (Lim 2007). This result shows that each item in the test is acceptable and valid to be used in the study. The data from the present study were analyzed using the AMOS 18 software. The study used the usual matching measurement index as the benchmark in determining the suitability of a model, such as root mean square error of approximation (RMSEA), comparative fit index (CFI), goodness of fit index (GFI), Tucker-Lewis fit index (TLI), and normed chi-square ( $\chi^{2} / \mathrm{df}$ ) (Hair et al., 2006).

\section{Confirmatory Factor Analysis}

Confirmatory factor analysis shows that the standard relations between factors and items are from 0.59 to 0.78 . Figure 2 shows that all the items for each factor in conceptual and procedural knowledge are above 0.40 and significant. The value of 0.40 is usually used in any factor analysis (Hashim and Sani, 2008). However, some conceptual (Pa2 and $\mathrm{Pa} 3$ ) and procedural (Pa6, Pa9, and Pa10) items do not meet such requirements, and they were excluded from the test. The chi-square index from the model is good and significant $\left(\chi^{2}=12.83, d f=4, \mathrm{p}<0.05\right)$ (Kline, 2005). Chi-square/df $(12.83 / 4=3.21), \mathrm{CFI}=0.98, \mathrm{GFI}=0.98$, and RMSEA $=0.09$. This result shows that the designed model is excellent (cf., Table 1).

Table 1. Confirmatory factor analysis of students' conceptual and procedural knowledge

\begin{tabular}{cc}
\hline Parameter & Coefficient \\
\hline CFI & 0.98 \\
\hline GFI & 0.98 \\
\hline RMSEA & 0.09 \\
\hline Df & 4 \\
\hline$\chi^{2}$ & 12.83 \\
\hline$\chi^{2} / \mathrm{df}$ & 3.21 \\
\hline
\end{tabular}

Note: CFI: comparative fit index; GFI: adjusted goodness-of-fit index; RMSEA: root mean square error; df: degrees of freedom; $\chi^{2}$ : chi-square goodness of fit. 


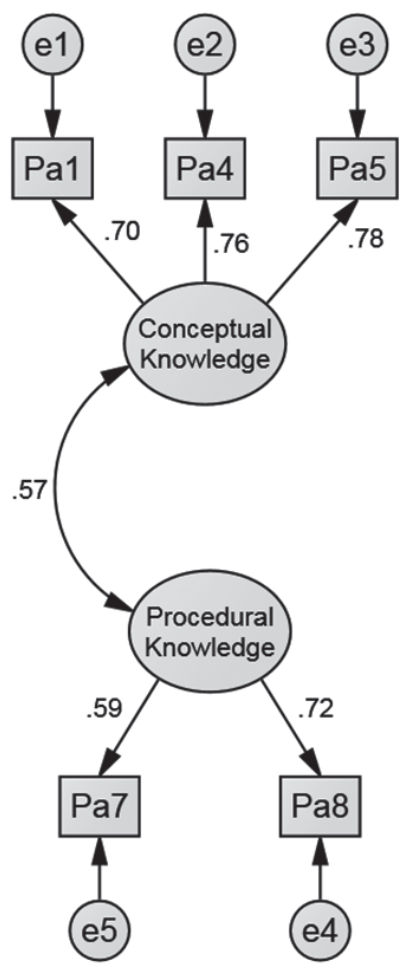

Figure 2. Confirmatory factor analysis model for students' conceptual and procedural knowledge

Figure 3. Standardized coefficients for the model of procedural knowledge mediating the relations between conceptual knowledge and academic achievement of students who used the GeoGebra method.

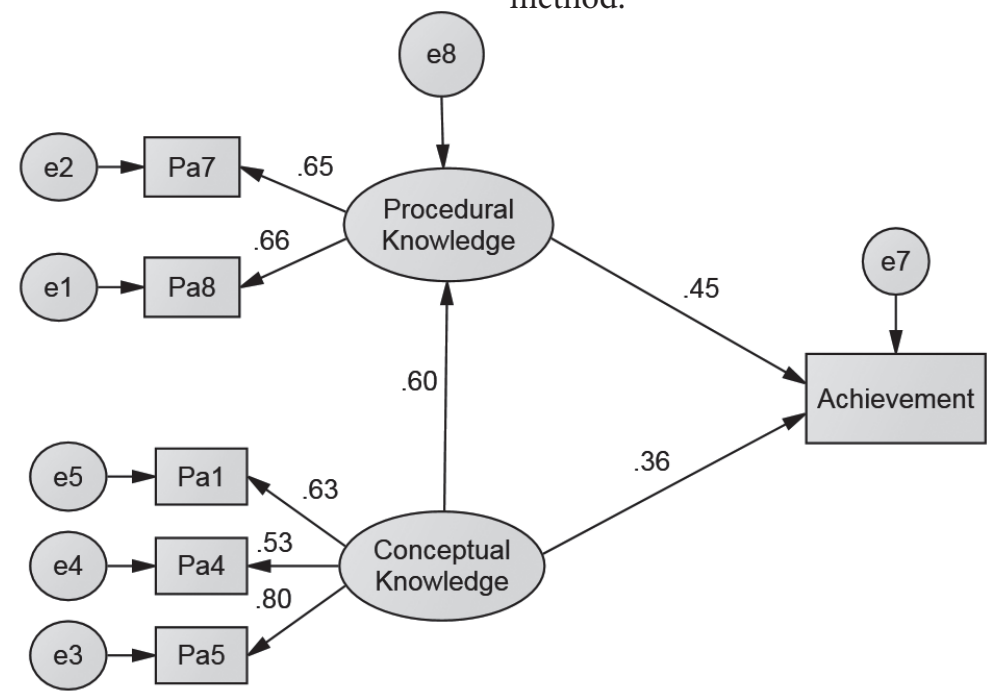




\section{Results}

Mediating role of conceptual knowledge and relation between procedural knowledge and achievement of students who used the GeoGebra method

The total effect of conceptual knowledge on academic achievement was significant $(\beta=.36, \mathrm{p}<0.05)$. Figure 3 shows that conceptual knowledge significantly predicted student procedural knowledge $(\beta=0.60, \mathrm{p}<0.05)$. Student procedural knowledge significantly predicted academic achievement after controlling for conceptual knowledge $(\beta=0.45, \mathrm{p}<0.05)$. The overall model fit was good. Chi-square/ df $(5.091 / 7=0.73)$, CFI $=1.0, \mathrm{GFI}=0.99$, and RMSEA $=0.01$. The mediation effect of student procedural knowledge was complete because the direct effect of conceptual knowledge on achievement was significant $(E d=0.36, \mathrm{p}<0.05)$, and the indirect effect of conceptual knowledge on achievement via student procedural knowledge was statistically significant $(E i=0.27, \mathrm{p}<0.05)$.

Mediating role of conceptual knowledge and relation between procedural knowledge and achievement of students who used the conventional method

Figure 4 shows that the overall model fit was good. Chi-square/df (13.32/7 $=1.90), \mathrm{CFI}=0.96, \mathrm{GFI}=0.97$, and RMSEA $=0.08$. Conceptual knowledge on

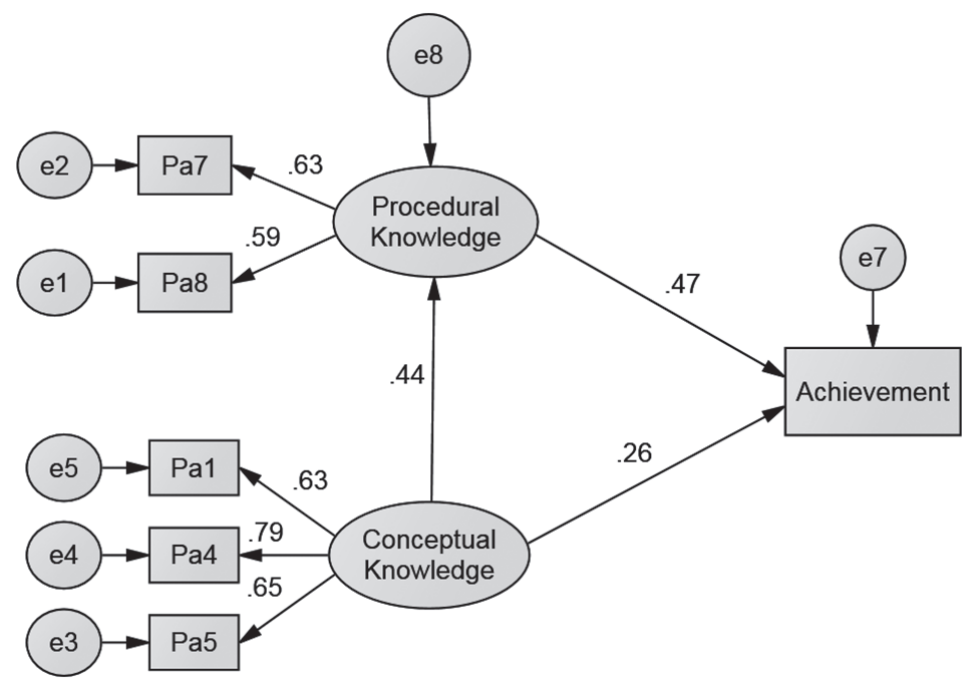

Figure 4. Standardized coefficients for the model of procedural knowledge mediating the relations between conceptual knowledge and academic achievement of students who used the conventional method. 
academic achievement was significant $(\beta=0.26, \mathrm{p}<0.05)$, and conceptual knowledge significantly predicted student procedural knowledge $(\beta=0.44, \mathrm{p}<0.05)$. Student procedural knowledge significantly predicted academic achievement after controlling for conceptual knowledge $(\beta=0.47, \mathrm{p}<0.05)$. The mediation effect of student procedural knowledge was complete because the direct effect of conceptual knowledge on achievement was significant $(E d=0.26, \mathrm{p}<0.05)$, and the indirect effect of conceptual knowledge on achievement through student procedural knowledge was statistically significant $(E i=0.21, \mathrm{p}<0.05)$.

\section{Discussion}

The findings show that the students who used GeoGebra in teaching and learning the mathematical limited function topic have the same model as the students who used the conventional method. The findings show that the students' procedural knowledge is the significant mediator in the relation between conceptual knowledge and student achievement. The difference between both models is the given contributing effect. The mediating effect of procedural knowledge on the students who used GeoGebra was higher than that on the students who used the conventional method. The direct contribution of procedural knowledge in student achievement also produced better results for the students who used GeoGebra than those who used the conventional method. The findings support the view of Hiebert and Lefevre (1986), who stated that conceptual knowledge is necessary in solving a basic problem, and specific procedural knowledge cultivates the required skills to solve a problem.

The findings of the present study show that both teaching methods use the same model in the form of procedural knowledge as mediator between conceptual knowledge and student achievement. The findings show that conceptual knowledge positively affects the increase in students' procedural knowledge and indirectly through it, thereby improving student achievement. These findings are similar to the view of Pesek and Kirshner (2000), who warned that learning procedures with shallow basic concepts would complicate the understanding of up-to-date concepts. This condition shows that conceptual knowledge and students' mathematical procedures go hand in hand. Conceptual knowledge can be considered as an effort to acquire students' mathematical procedures. The findings show that students' conceptual knowledge positively affects their achievement. However, the effect is still considered low and significant. This result demonstrates that students' mathematical procedural knowledge has a higher effect on student achievement than students' conceptual knowledge. 
The use of GeoGebra shows a better effect on the increase in students' conceptual and procedural knowledge and their achievement. This result is caused by the fact that GeoGebra can provide easy steps for students to acquire concepts and procedures in solving a problem. This study strengthens the statement of Rittle-Johnson and Koedinger (2005), who stated that steps or actions in solving a problem could facilitate students' learning. The present study shows that the use of the conventional method also positively affects the increase in conceptual and procedural knowledge and student achievement. Both teaching strategies provide similar effects on the relation between conceptual, procedural knowledge, and student achievement. The conventional method provides information that mathematical concepts and procedures can be explained through various forms of teaching (Rico, 2006). Thus, teaching using the conventional method explains the mathematical concepts using standard problems similar to those in textbooks. However, using GeoGebra, mathematical concepts can be explained by providing different real-life situations.

Although the mediating effect of procedural knowledge in the relation between conceptual knowledge and student achievement is similar for the students who used GeoGebra and those who used the conventional method, using the conventional method has a higher mediating procedural effect than using GeoGebra. Meanwhile, the direct effect of conceptual knowledge on student achievement is higher in those who used GeoGebra than those who used the conventional method because the latter are provided with longer time to perform mathematical procedures. By contrast, the students who used GeoGebra obtain more conceptual information and less exposure to the mathematical procedures. Harper (2007) stated that the use of computer technology in teaching and learning could lessen students' procedural ability. Engelbrecht et al. (2005) stressed that this situation could happen because of students' new strategies in using oral, frames, algebra, and visual with low procedural knowledge. This condition resulted from the limited time frame provided in the teaching and learning process.

\section{Conclusion}

The presented study shows the importance of conceptual and procedural knowledge as mediator for student achievement. Procedural and conceptual knowledge are necessary aspects in mathematical knowledge. This matter can be highlighted along with the conceptual skills gained to increase procedural knowledge. GeoGebra is a tool that can help students to increase their conceptual and 
procedural knowledge and achievement. GeoGebra can be used to plot a graph and other facilities in solving problems related to mathematical concepts and procedures. The study provides relevant information in designing exercises for teachers. Demand for more studies to prove the effect of GeoGebra in teaching and learning mathematics that involve various problems to be solved is high. In addition to students, teachers should be included in similar studies that involve knowledge, skills, and use of GeoGebra and students' performance.

\section{References}

Ahmad Fauzi Mohd Ayub, Tengku Mohd Tengku Sembok and Wong Su Luan. (2009). The use of computers in teaching and learning calculus students in the Diploma: Ratings on packages TEMACCC (Ed.), Ahmad Fauzi Mohd Ayub and Aida Suraya Md. Yunus. Mathematic Education and Technology Applied, Putra University of Malaysia. pp. 274-300.

Aizikovitsh, U.E and Radakovic, N. (2011). Using GeoGebra for Understanding and Supporting Students' Learning of Probability. Proceedings Of The Second North American GeoGebra Conference: Where Mathematics, Education and Technology Meet. University Of Toronto. June 17-18, 2011. ISBN 978-0-920233-65-8 (CD).

Best, J.W and Kahn, J.V. (2003). Research in education (Ed.), Boston: A Pearson Education Company.

Carpenter, T.P. (1986). Conceptual knowledge as a foundation for procedural knowledge. In: J Hibert (Ed.), Conceptual and procedural knowledge: The case of mathematics. Hillsdale, NJ, Lawrence Erlbaum Assosiates. pp. 113-131.

Engelbrecht, J., Harding, A., and Potgieter, M. (2005). Undergraduate students' performance and confidence in procedural and conceptual mathematics. http://ridcully.upac.za/multi/ conceptualmath.pdf.

Hair, J., Black, W., Babin, B., Anderson, R., Tatham, R. (2006). Multivariate data analysis (6 $6^{\text {th }}$ Ed.), Uppersaddle River, NJ, Pearson Prentice Hall.

Harper, J.L. (2007). The use of computer algebra systems in a procedural Algebra course to facilitate a framework for Procedural understanding. Dissertation Doctor of Philosophy. Montana State University. ProQuest.

Hashim, R.A., and Sani, A.M. (2008). A Confirmatory Factor Analysis of Newly Integrated Multidimensional School Engagement Scale. MJLI, 5: 21-40.

Hiebert, J. 1986. Conceptual and Procedural Knowledge: The case of mathematics. Hillsdale, Lawrence Erlbaum Associates.

Hibert, J., and Lefevre, P. (1986). Coceptual and procedural knowledge in mathematics: An introductory analyis. In: J. Hibert (Ed.), Conceptual and procedural knowledge; the case of mathematics, Hillsdale, NJ, Lawrence Erlbaum Associates. pp. 1-23.

Hope Marchionda. (2006). Preservice teacher procedural and conceptual understanding 
of fractions and the effects of inquiry based learning on this understanding. Unpublished Doctoral Dissertation. Clemson University.

Juter, K. (2006). Limits of functions: University students' concept development. Ph.D thesis, Lulea University of Technology.

Karno To. (1996). Identification Test Analysis (Introduction to Computer Program ANATES). Bandung: Educational Psychology and Guidance FIP IKIP.

Kiuru, N., Pakarinen, E., Vasalampi, K., Silinskas, G., Aunola, K., Poikkeus, A.M., Leena, R., Metsäpelto, Lerkkanen, M.K., and Nurmi, J.E. (2014). Task-Focused Behavior Mediates the Associations Between Supportive Interpersonal Environments and Students' Academic Performance. Psychological Science published, 1: 1-7. DOI: 10.1177/0956797613519111.

Kline, R.B. (2005). Principles and Practice of Structural Equation Modeling (2nd Edition). New York: The Guilford Press.

Lim, C.H. (2007). Educational Research: Quantitative and Qualitative Approaches. Kuala Lumpur: McGraw Hilll Education.

Nesher, P. (1986). Are mathematical understanding and algorithmic performance related? For the Learning of Mathematics, 6(3): 2-9.

Oldknow, A., and Taylor, R. (2000). Teaching Mathematics with ICT. London: Continuum. Pesek, D.D., and Kirshner, D. (2000). Interference of instrumental instruction in the subsequent relational learning. Journal for Research in Mathematics Education, 31:524-540. Doi: $10.2307 / 749885$.

Pettersson, K., and Scheja, M. (2008). Algorithmic contexts and learning potentiality: A case study of students' understanding of calculus. International Journal of Mathematical Education in Science and Technology, 39(6): 767-784. Doi: 10.1080/00207390801986908.

Rico, L. 2006. Marco teôrico de evaluaciôn en PISA sobre matemâticas y resoluciôn de problemas. Revista de Educaciôn, extraordinario, 1: 275-294.

Rincon, L.F. (2009). Designing Dynamic and Interactive Applications Using GeoGebra Software. Kean University. ERIC Full text and Thesis.

Rittle-Johnson, B., and Koedinger, K.R. (2005). Designing knowledge scaffolds to support mathematical problem solving. Cognition and Instruction, 23(3):313-349. Doi: $10.1207 /$ s!532690xci230.

Robiah Sidin. (1994). Education in Malaysia. Challenges of the Future. Kuala Lumpur: Fajar Bakti.

Rohani Ahmad Tarmizi, Che Wan Rosida Wan Hasan, Ahamd Fauzi Mohd Ayub, Kamariah Abu Bakar, and Aida Suraya Md Yunus (2009). Use of graphing calculators in the teaching and learning of mathematics. In: Ahmad Fauzi Mohd Ayub and Aida Suraya Md Yunus. Mathematics Education and Technology Application. Putra University of Malaysia.

Selden, A., and Selden, J. (1992). Research perspective on conceptions of functions: summary and overview. In: Harel, G. and Dubinsky E (Ed.), the concept of function: aspects of epistemology and pedagogy. Washington, DC, Mathematical Association of America. pp. 1-16. 
Setu Budiardjo (2011). Adoption Jigsaw cooperative learning methods to improve the learning outcomes of students class XII-2 light transport techniques SMK Negeri 5 Semarang in resolving the derivative function. Journal AKSIOMA. (2).

Sivin-Kachala, J., and Bialo, E.R. (2000). Research Report on the Effectiveness of Technology in Schools 7 Edition. Washington, DC, software Information Industry Association.

Slameto (2003). Learning and Factors Affecting. Jakarta: Rhineka Cipta.

Star, J. (2005). Reconceptualizing procedural knowledge. Journal for Research in Mathematics Education, (36): 404-411.

Tall, D.O., and Vinner, S. (1981). Concept image and concept definition in mathematics, with special reference to limits and continuity. Educational Studies in Mathematics, (12): 151-169. Doi: 10.1007/BF00305619.

Williams, S. (1991). Models of limits held by college calculus students. Journal for Research in Mathematics Education, 22(3): 219-236. Doi: 10.2307/749075.

Zainuddin Awang (2012). Structural Equation Modeling Using Amos Graphic: UiTM Press. 